This is an electronic reprint of the original article. This reprint may differ from the original in pagination and typographic detail.

Please cite the original version: Tossavainen, P. J. \& Kaarti, V. (2015) Don't the Cobbler's Children Have Shoes? A Service Design Lens and Visualization Tools in Action in Higher Education. International Journal of Innovation, Management and Technology 6:5, 320-325. 


\title{
Don't the Cobbler's Children Have Shoes? A Service Design Lens and Visualization Tools in Action in Higher Education
}

\author{
Päivi J. Tossavainen and Virpi Kaartti
}

\begin{abstract}
Service design has become a known framework within industry. Service design in business education can be seen as a vehicle to enhance innovativeness through visualization of holistic service development process. Evidence to this is a significant increase in studies that investigate the topic from different perspectives. However, the use of service design inspired visualization in education has not yet been discussed. To address this gap, we examined, how visualization is used in teaching of Bachelor's and Master's Degree Programs. The investigation resulted in identifying the key aspects that underpinned the service design inspired visualization techniques. We integrate these key aspects into an overarching visualization roadmap for education purpose, which provides a substantial contribution by creating an integrated analysis of this phenomenon. Furthermore, we suggest three strategies for teachers in applying visualization in their education.
\end{abstract}

Index Terms - Service design, visualization, higher education.

\section{Visualization AND SERVICE DESIGN LENS IN Higher EDUCATION}

Visualization and visual representations have a place in education. Yet, relatively little is written about this topic. We found that [1] discusses visual illustrations in learning materials and his study confirmed that illustrations help students to store the new information in memory. Reference [2] suggests the distinction between static and dynamic displays that could be extended towards interactive media use in learning. This literature refers to the available materials to be used. Reference [3] agrees that the visual methods can aid the study of classroom as these methods can slow down the act of looking interaction. He continues that multiple visual methods that can be used with the contemporary word and number based approaches should be developed. Thus, our standpoint is the creation of visualizations as a learning outcome of students. This paper explores how to use visualization (or visual representations) in higher education (HE). In higher education institutes (HEIs) education with students - on both Bachelor and Master level - focus on solving complex problems and challenges. For this they need different skills. Thus, also teachers need to use and educate these skills. In this paper, we focus on one type of skills: visualization. Why is visualization an important skill in higher

Manuscript received July 6, 2015; revised September 12, 2015.

The authors are with Laurea University of Applied Sciences (UAS), Finland (e-mail: paivi.tossavainen@laurea.fi, Virpi.kaartti@laurea.fi). education and later on in professional life? There are several reasons such as the complexity of challenges students will solve during their education. The use of visualization is suggested [4] for the following reasons: it enhances the creativity in problem solving, students become more interactive, students can develop ideas (from vision to execution), translate and elaborate ideas, to see possibilities better, and to compare change with status quo. In addition, benefits include working and creating solution together interactively.

The second reason is that service design (SD) has become a central framework within industry to innovate service. For industry, service design approach brings new methods, techniques and tools to improve and innovate service offering, processes, and organization. For universities and higher education institutes, service design has mainly been a subject to teach. Service design approach is then brought to professional life and is a key competence for future business practitioners. With regards to HEIs and education, service design may bring enormous potential.

Moreover, learning requires hands on approach on subject/ topic to be educated. For example, at Laurea University of Applied Sciences (Laurea) pedagogical approach called Learning by Developing (LbD) is very work life oriented. This operational model is based on authencity, partnership, experiential learning and research. LbD places students in the center of his/ her learning experience. Laurea is also the pioneer in the world in education of service innovation with design. These two orientations complement each other. Visualization is a way to illustrate the authencity and experiences, and is thus incorporated in education. From the pedagogical point of view, visualization skills learned in HE will build capabilities, skills, and competences to future business practitioners.

The aim of this paper, therefore, is to provide a greater understanding of service design inspired visualization approach by investigating and critically integrating the main aspects of visualization in education through review of cases of how teachers use it in practice. Thus, this paper contributes to bridging service design and especially the visualization within higher education.

The remainder of this paper is organized as follows. First, we begin by introducing service design approach focusing on visualization techniques in education. Second, we explain our methodology. Third, we analyze the empirical findings and suggest strategies for teachers. Finally, conclusions are drawn and future research directions are offered. 


\section{SERVice Design Lens In Higher EducAtion}

In recent decades several influential transformations within our business society have shaped the world we live in and thus the education we provide. For example, [5] suggested that the society is moving from a product-centered to an experience-centered economy. Then, [6], [7] stressed the service dominant logic viewpoint over the still dominant industrial logic, and lately the transformation to the digital service economy. In general terms, we talk about the transformation to service society. Service research can be examined from strategic, development, or execution levels [8] In this paper, we choose the development level. Accordingly, the development priorities on theoretical perspective include service innovation stimulation, enhancement of service design and optimizing service networks and value chains [8]. Service research have taken insights and methods from other disciplines. In service, complex socio-technical solutions are created preferably together with the users, customers or other stakeholders. While the development work in the beginning is primarily abstract, we need design approach to discuss the issues. This design thinking is elaborated [9] as movement is design spheres rather than linear milestones. Accordingly, through inspiration and ideation the quick prototyping concretizes the vision. Design thinking is a relatively new perspective, which is built on traditional, industrial/ product, and organizational design. The service design approach - on the other hand - is uniquely oriented to service specific design needs which is rooted in the design culture. Thus, the design discipline has influenced largely on service design. Reminded is [10] that a set of service design tools can help visualizing and testing the service experience and the interface, is adopted and adapted from design disciplines and practices focusing on user-centricity and interaction. Visualization is identified by several authors in the design management field as one of the skills and qualities of designers [11].

Service design is part of the larger service development process. Typically each phase/ step in the development process includes a variety of methods and tools to choose from [12] Similarly as service development competences are distinctive competences, which rely on service theories (knowledge) and their implications in practice [13], [14] are the service design competencies distinctive. Furthermore, they relate to on both business domains: service provider's and customer's domain.

Service design involves with strategic thinking in service business and it focuses on developing service from the customer point of view. The customer-centricity is a key premise in all activities conducted. For this, there are certain models, techniques and tools to be used. Services are often at least partly immaterial, dynamic and complex constructs, and therefore the development of them should be considered as dynamic and iterative process. The challenge in developing service is that the outcomes and results of the partial or final service is often illustrated visually, in mockups, or even as prototypes. To conclude, service design requires modern way of getting deeper understanding of the customer needs, and recognizing the needs from all service participants.

Recently, Ref. [15] has described the service design through specific schools of thought from interface design, to experience design, to interdisciplinary such as service marketing and management issues. This shows the great interest in service design as methodology, way of working and practice. Likewise, Ref. [16] has explained the service capabilities as function of service logic adoption and use of service driven methods. Positioning the service design has been of a great interest and as a discipline of practice and academic field. Recently topic has also been covered in doctoral dissertations [15], [17]-[18].

Our intake on service design and working definition for this paper is that service design is about planning, developing and innovating service through service development process and with service design methods. The purpose of service design is to create user/ customer -centric service experience that meets the needs and demands of the users or customers and fulfills the service provider's business objectives. Service development and design can be seen as vehicles for improved business. With tangible methods and guidelines, new methods, competencies and skills can be learned [19].

Service design is about visualizing at least partly abstract issues. Reference [4] created a visualization set of questions that can be also used to help teachers in guiding visualization process through a set of categories the teacher can ask the students to answer which are dealing with 1) simple or elaborated view 2) quantitative or qualitative issue 3) vision or execution 4) individual or comparison or 5) change or status quo.

Business related information is often illustrated. Moreover, visualization can be free form or templates can be used. For example, business models [20] and service dominant strategies [21] can be visualized with a help of a canvas template. Likewise, visualizing the customer service experience, which is typically build on service touchpoints, service moments and customer journeys, can be with variety of templates available. Service blueprint - also available as a template - describes the clear, coherent, and consistent description how the service unfolds. This is a process description including the customer activities lacking in typical business process charts. These are few examples of the amount of service design templates available. These templates and related techniques form the basis for HEIs to educate their students.

\section{How SERVICE DESIGN AND VisuAlization TECHNIQUES ARE USED IN HIGHER EDUCATION - CASE LAUREA}

As we have discussed in general terms what service design is, how the activity of planning and organizing people, infrastructure, communication and material components of a service in order to improve its quality and the interaction between service provider and customers emerges, these skills need to be educated. The purpose of service design methodologies is to design according to the needs of customers or participants, so that the service is user-friendly, competitive and relevant to the customers. The service experience is a central concept to the service design. Visualization helps to understand the service and communicate issues during and after service is developed.

At Laurea, a specific master's degree program in service 
innovation and design, incorporates business with service development in order to educate business practitioners with specific service design skills. This choice was made early 2007 and the program was established in 2009 globally at the first time. Since then, there are other degree programs focusing on service design. This is because service designers require a broad set of creative skills as well as extensive life experience and business managers will do need these skills [22]. Despite the progress in developing educational programs, the design and business studies involved in the development of new service are still hitherto essentially remained unconnected [15]. Therefore, we like to discuss the experiences from Laurea. Further, our aim is to encourage other HEIs and teachers to use service design lens and visualization tools in their education.

The question do the cobbler's children have shoes challenges whether the teachers in HEIs use the service design lens and visualization in their education or not. Factors that inhibit the use of visualization techniques may also relate to how people approach the visual problem solving. Reference [4] identifies accordingly three types of people: 1) people who can't wait to jump and start illustrating, 2) people who are happy to watch other people doing illustrations, and 3) people who sit quietly in the back because they think visualization is not useful at all. Each of these types of people exist in classrooms and also in work places. All three types have a purpose in creating something that is visible to all and ready for discussion. All these apply to both teachers and students. However, teachers need to learn these competences and use them in classrooms in order to teach them to students.

Several factors can either facilitate or inhibit the operationalization of visualization techniques. As [23] remind that visualization allows people to be more expressive than with words. The factors that facilitate visualization has nothing to do with the skill of drawing. Visualization is not about how well one can draw. Or in more general terms about creativity. Everyone can draw [4], [23]. It is an attitude and decision to express one's ideas. One can practice visualization and move from simple to more elaborated styles.

In this paper, we elaborate with few examples how teachers can use the service design lens and visualization in their education. However, the educational cases we discuss in this paper are not only subject to this one Master's degree program. We show how the same visualization can be used in Bachelor level studies and in other disciplines too.

How visualization techniques are operationalized in education from the teacher's perspective? What are the factors that contribute the use? From our personal experience, education is often based on quantitative norms. Student outcomes are evaluated based on the reports they write. The report instructions are often defined on number of pages, font size, reference technique, and structure, but not so much in detail on the content wise. Based on our experience teachers prefer the fixed and clear standards, and so do many students as well. However, we suggest that even with these fixed report techniques and guidelines, visualization could bring much needed illustrations in order to understand the topic more holistically. Furthermore, during the course/ study unit work, interim parts of the assignments could be presented in format of visualizations.

For this paper, the authors investigated their teaching portfolio in order to find out how much visualization is used. We selected few examples to highlight the course, technique and the variety of the outcomes. This examination is presented in Table I. We used this investigation to build a framework for visualization in HEI context.

The development of the framework (illustrated in Fig. 1) takes place as follows: First, we took a look of various courses and mapped out in the table (see Table I in Appendix). Then we used a thematic mapping of the individual methods, techniques and tools. This resulted in 2 by 2 matrix in which the dimensions are linked to the use of the service design inspired visualization and other visualization tools in education. The dimensions were related to first, simple and complex explanation power of visualization technique, and secondly to the explanation format standalone (written reports and power point presentations) or requiring narration to be understood. Then, we divided the different techniques under four groups (A, B, C, D). Finally, we illustrate the strategies for teachers to extend the use of service design lens and visualization in their education.

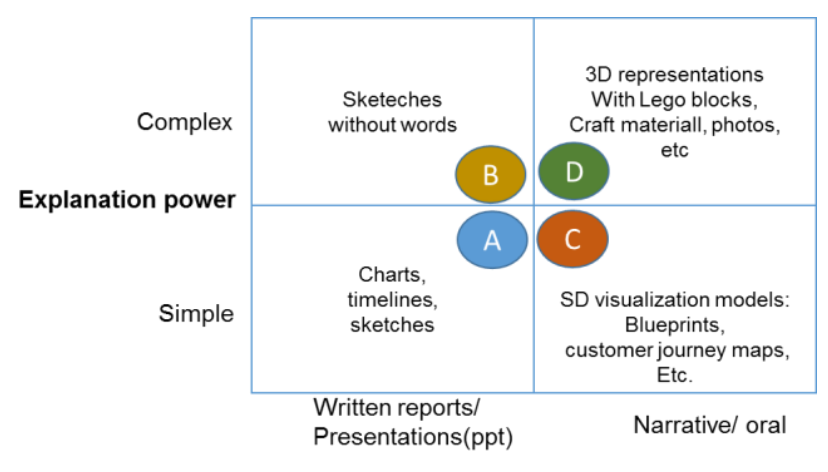

Explanation format

Fig. 1. Framework of visualization techniques.

Next, we discuss each quadrat of the matrix separately and provide further information. Quadrat A represents the simple drawings, charts, time lines, sketches that are commonly used (see Fig. 2). In order to investigate or learn more about the simple visualization techniques, please see [4] detailed instructions, exercises and explanations.

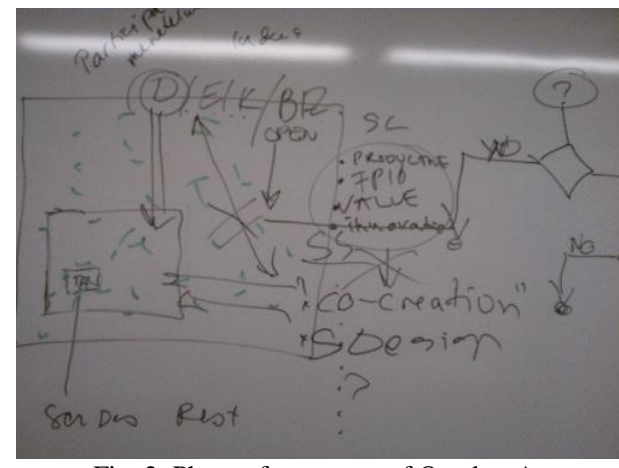

Fig. 2. Photo of outcomes of Quadrat A.

Quadrat B represents basic visualizations used without the written text (see Fig. 3). This challenges the students to focus on illustrations. Presentation of these illustrations always requires a narrative to be fully comprehensive. 


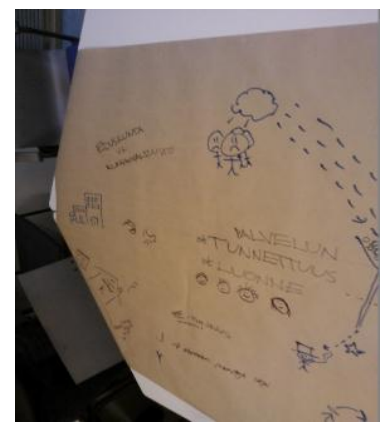

Fig. 3. Photo of outcomes of Quadrat B.

Quadrat C represents the forms of service design inspired visualization in education (see Fig. 4). These includes structured models such as business model canvases, service blueprint, customer journey map, storytelling diagram, etc. In order to investigate more about the service design visualization tools, please see [24], [20] for detailed instructions and models. This is service design -book is also the first book about service design thinking has an explicit focus on doing through a broad selection of short descriptions of service design methods [24].

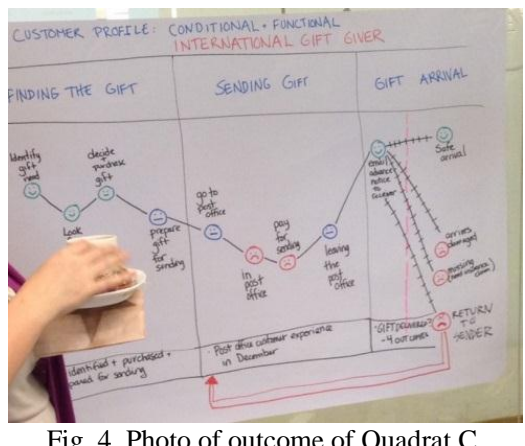

Quadrat D represents a mixed visualization techniques (see Fig. 5). These includes combinations on visualizations by drawing and other building blocks for 3D illustrations such as Lego blocks and crafting materials. For this, one can use magazines for example cutting out concepts, ideas, or customer types. Further, all kind of materials such as play cards, cardboard, craft materials, are useful in creation of $3 \mathrm{D}$ visual representations.

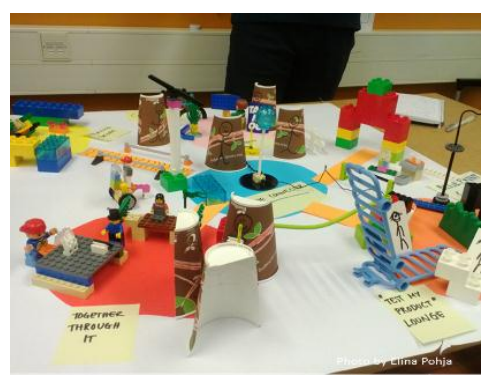

Fig. 5. Photo of outcomes of Quadrat D.

The photos (Fig. 2-Fig. 5) provided in this chapter are taken from the Laurea education and are representative as what the students can accomplish.

\section{FINDINGS}

Visualization and the service design lens supports the selected Learning by Developing (LbD) approach in pedagogy at Laurea University of Applied Science. Service design brings tools for education. In this paper, we have shown that visual tools can be part of education in HEI Besides the obvious reasons, visual tools increase the interaction and co-creation of abstract issues into concrete representations. Visual outcomes suggested in our roadmap, transfer the discussion from person to matters and from touchpoints to the whole experience and therefore allows new solutions to emerge. We operationalized the service design lens and visualization techniques with a help of the matrix. The final outcome of the matrix is presented in Fig. 6.

The explanation power refers to the characteristics of the problem or challenge to be solved. The simple issue can be visualized with simple charts. For example some statistical information are presented in pie chart. These are accompanied typically with written data. A more complex issues can be visualized in similar way, but they are not accompanied by written information. Thus they should be explanatory by themselves. Similarly, the format axis refers to the presentations needing oral explanations or not. For example, in quadrat $\mathrm{D}$, complex socio-technical issues can be visualized through the use of drawing and 3D materials such as Lego blocks, pictures, tape, etc. provided to the users.

At Laurea, Master's students also use sidlaurea.com blog during their education. While the instructions for the blog use are fairly simple, the blog entries are not. As a finding of the service lens and visualization achievement, the blog entries are very visually explanatory. This is a clear indication that the learning of the visualization has taken place.

Finally, Fig. 6 depicts the trajectories of strategic choices for teachers in business education. Based on our analysis, we found three different strategies for teachers to follow.

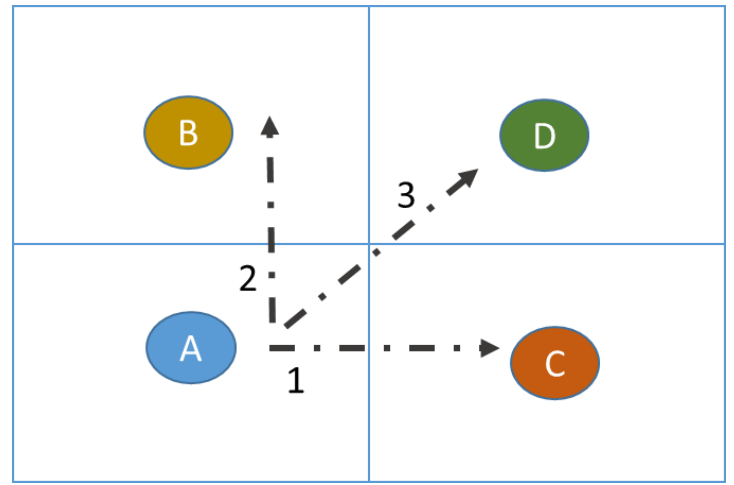

Fig. 6. Strategies for teachers to enhance service design inspired visualization techniques.

The first strategy is called the low threshold strategy. It offers the clear guidelines and models to follow so being easy to take into use with students that are non-familiar with visualization techniques. The second strategy we named as the high threshold strategy. It is a leap to the totally different way of working and demands new skills to get started. The third strategy is the most extended and is called the multifaceted strategy. As the previous one it also a leap to the totally different way of working, but it demands several different skills to get started. 


\section{Conclusions And Discussion}

The service design inspired visualization techniques in HEI education is largely seen as one approach to improve education/ innovation by facilitating the use of visualization-related knowledge and experience across study units. Importantly, this collaboration has two distinct characteristics/ factors. First, factors that facilitate the use. Second, the inhibiting factors. WE have presented three strategies to overcome these factors. Moreover, we have investigated the current use of visualization in education at Laurea, and operationalized this with the recent literature in to a framework.

Service design is a holistic approach, which considers in an integrated way strategic, system, process and touchpoint design decisions. At the same time, it is a systematic and iterative process that integrates user-oriented, team-based, interdisciplinary approaches and methods, in ever-learning cycles, in which different people can contribute. Multiple stakeholders work collaboratively and co-create together service that fits the needs of the customers and business criteria of the service provider. As such the service design approach provides a process to follow, which is a systematic way of doing things. Model for the project, because there must be a beginning and an end. And techniques filled with use of various methods and tools, because it is an innovative way.

This paper contributes the both education and visualization literature by providing rich examples, operationalized framework, and necessary strategies to proceed with service design inspired visualization techniques in higher education.

To conclude suggestions for further research, we detected several interesting issues during this study. Firstly, student perspective on service design inspired visual skills education. To have more balanced view on suggested framework and strategies would require investigations from a student perspective. Secondly, teachers require motivation, help and training for using the visualization. Studies are called for investigations towards the needs of the teaching staff. Thirdly, more theoretical research is needed for the application of the service design approach in higher education. To conclude, the higher education gives an interesting context to examine pedagogical modernization.

\section{APPENDIX 1}

TABLE I: EXAMPLES OF STUDY UNITS VISUALIZATION IS USED (BBA AND MBA) AND THE MOTIVATIONS TO USE VISUALIZATION TECHNIQUES IN EDUCATION

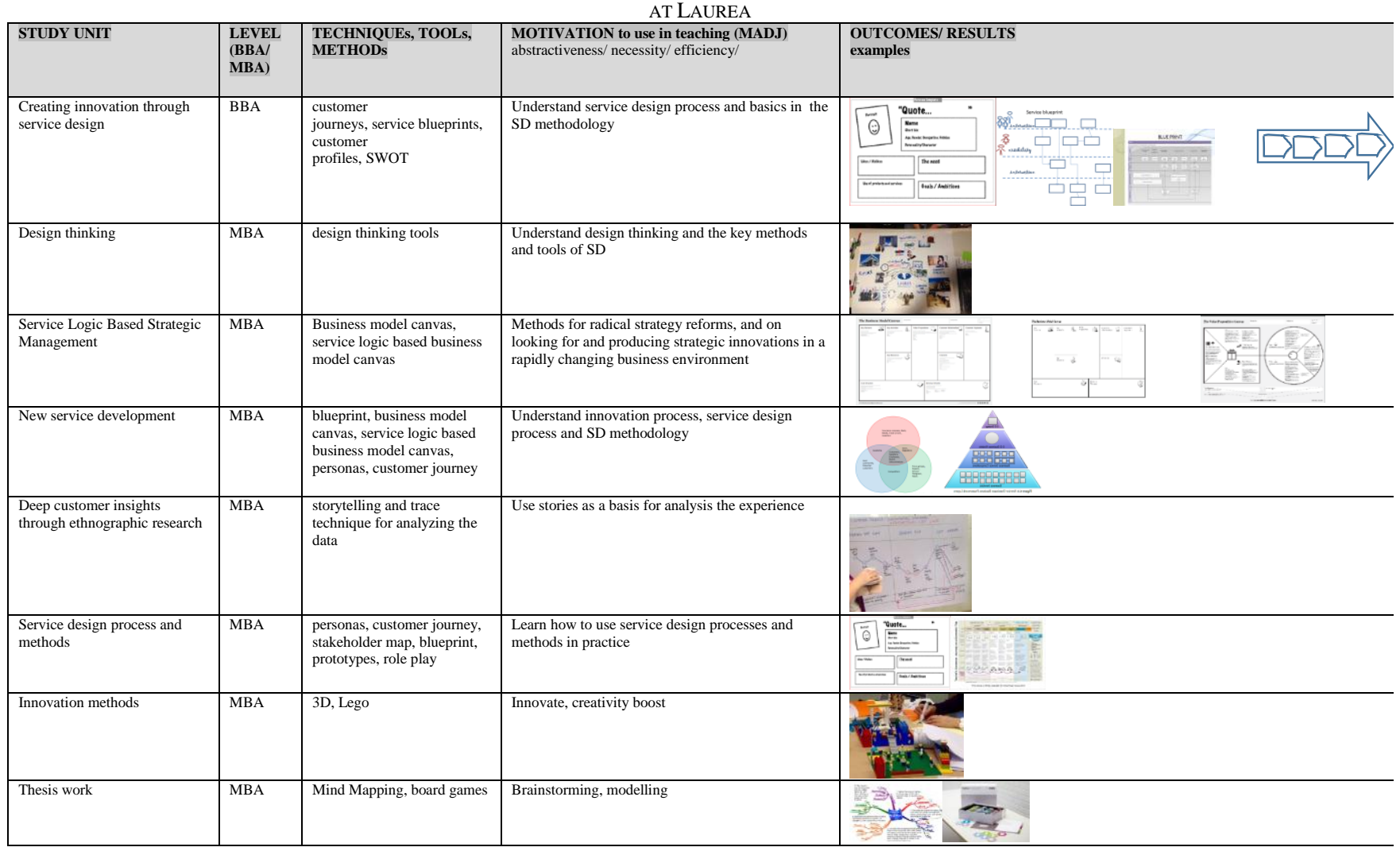

\section{REFERENCES}

[1] D. Lewalter, "Cognitive strategies for learning from static and dynamic visuals," Learning and Instruction, vol. 13, pp. 177-189, 2003.

[2] M. Hegarty, "Dynamic visualizations and learning: getting to the difficult questions," Learning and Instruction, vol. 14, no. 3, pp. 343-351, 2004

[3] J. Prosser, "Visual methods and the visual culture of schools," Visual Studies, vol. 22, no. 1, pp. 13-30, 2007.

[4] D. Roam, Unfolding the Napkin, The Hands-on Method for Solving Complex Problems with Simple Pictures, Portfolio/ Penguin Group. NY, USA, 2009, p. 286.
[5] B. J. Pine II and J. H. Gilmore, Harvard Business Review, July-Aug, 1998, pp. 97-105.

[6] S. L. Vargo and R. F. Lusch, "Evolving to a new dominant logic for marketing," Journal of Marketing, vol. 68, pp. 1-17, January 2004.

[7] S. L. Vargo and R. F. Lusch, "Service-dominant logic: Continuing the evolution," Journal of the Academy of Marketing Science, vol. 36, no. 1 , pp. 1-10, 2008.

[8] A. L. Ostrom, M. J. Bitner, S. W. Brown, K. A. Burkhard, M. Goul, V. Smith-Daniels, H. Demirkan, and E. Rabinovich, "Moving forward and making a difference: Research priorities for the science of service," Journal of Service Research, vol. 13, no. 1, pp. 1-33, 2010. 
[9] T. Brown, "Design thinking," Harvard Business Review, June, pp. $84-92,2008$

[10] A. Meroni and D. Sangiorgi, Design for Services, Gower Publishing, Farnham, UK, 2011, p. 222.

[11] K. Michlewski. Design Attitude, Gower Publishing, Farnham, UK, 2015, p. 262

[12] S. Moritz, Practical Access to Service Design, KISD. Köln International School of Design, Germany, 2005, p. 125.

[13] C. Grönroos, Service Management and Marketing, Customer Management in Service Competition, WSOYpro, 2009, p. 565

[14] J. Ojasalo and K. Ojasalo, "Creating competences in service innovation and design, The SID Master's programme for practitioners combines business and design competences," Touchpoint, vol. 3, no. 3, pp. 58-59, 2011

[15] K. Wetter-Edman, "Design for service: A framework for articulating designers' contribution as interpreter of users' experience," $\mathrm{PhD}$ Dissertation, the University of Gothenburg, Sweden, p. 248, 2014.

[16] P. J. Tossavainen, "The Service capabilities: Steps to Service Designed Business. Innovative Service Perspectives," in Proc. the AMA SERVSIG International Service Research Conference, Hanken School of Economics, Helsinki, Finland, June 7-9, 2012, p. 87

[17] F. Segelström, "Stakeholder engagement for service design: How service designers identify and communicate insights," $\mathrm{PhD}$ Dissertation, Linköping University, Linköping. Sweden, 2013, pp. 185.

[18] Q. Han, "Practices and principles in service design. Stakeholders, knowledge and community of service," $\mathrm{PhD}$ Doctoral thesis, University of Dundee., Dundee, UK, p. 274, 2011.

[19] P. J. Tossavainen, L. Alakoski, and K. Ojasalo, "Building a service-centric business model in SMEs in the business-to-busines context," in Proc. ICSSME 2012: International Conference on Service Science, Management and Engineering, Dubai, UAE, October 8-9, 2012, issue 70, pp. 283-292.

[20] A. Osterwalder and I. Pigneur, Business Model Generation: A Handbook for Visionaries, Game Changers and Challengers, Willey, New Jersey, 2010, p. 288.

[21] E. Luftenegger, P. Grefen, and C. Weisleder, "The service dominant strategy canvas: Defining and visualizing a service dominant strategy through the traditional strategic lens," Beta Working Paper series 383 , NUR, Eindhoven, The Netherlands, 2012.

[22] Gayner Aaltonen. Service design. (2010). The Guardian, Media Guardian. [Online]. pp. 1-10. Available: www.guardian.co.uk/service-design.

[23] A. Polaine, L. Lovlie, and B. Reason, Service Design. From Insight to implementation, Rosenfeld Media. NY; USA, 2013.

[24] M. Stickdorn and J. Schneider, This is service design, BIS Publishers. Wiley, 2010, p. 384.

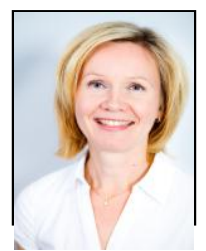

Päivi J. Tossavainen is Principal Lecturer (Teacher's Pedagogical Qualification, certified) at Laurea University of Applied Sciences (UAS) in Finland. She obtained her Master's Degree in International Business from University of Vaasa (Finland) in 1994 and the Doctorate Degree in International Business at Helsinki School of Economics (Aalto University, Finland) in 2005.
Her current teaching commitments focus on the Master's level programs, especially in business management (such as strategic management, management of business networks, innovation management), service business, service innovation and design, and research methodology (action research). She is a supervisor of Master's thesis work in two degree programs She is also a frequent lecturer in Bachelor's level degree programs with topics such as research methodology and service development and design. Before Laurea UAS, she had a strong 15-year industry career in developing the global operations of a multinational enterprise (Nokia/ Nokia Mobile Phones). Her managerial work experience comes from implementing large scale strategic change programs (logistics and supply chain management), complex socio-technological system implementations (enterprise resource planning system, ERP), and transformation from product-driven enterprise to service-driven enterprise.

Her research interests are in development initiatives especially related to service marketing and management topics. She collaborates with researchers and business practitioners to explore and investigate how service orientation changes organizations, how to implement service thinking, and how to promote of service development and service design. She has recently led two externally funded service research projects: 'Service Innovation through Strategic Stakeholder Integration 2010-2014 and 'Transferring Service Knowledge to SMEs (2010-2012). Dr. Tossavainen is an active member of academia and frequently presenting her research at academic conferences.

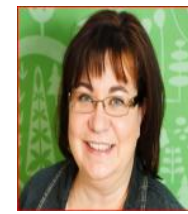

Virpi Kaartti is Head of the Master Degree Program in Service Innovation and Design at Laurea University of Applied Sciences in Finland. She has her background both in education and in business. Her teaching responsibilities included teaching business management, service marketing, supply chain management, and supervising thesis work in Bachelor's degree programs. Currently, at Master's degree programs, her teaching focuses on service development, service design, and strategic management. Besides leading the Master's degree program in service innovation and design, she is actively participating to the R\&D projects as a project manager or researcher. Her research interests are in the area of service marketing and management and service design. In academia, she has been a member of the development team which created the SID program and has implemented the program since 2009. She is chair of the Advisory Board in the Master's Program in Service Innovation and Design. She is member of the special interest group in the Finnish Service Alliance focusing on "segmentation, predictive analytics and targeting". She has initiated and organized several international Service Innovation \& Design seminars at Laurea, and Nordic ServDes2012 Conference in Finland together with her colleagues. She has an extensive managerial working experience in retail industry focusing on business development and marketing. 